\title{
Erratum to: An elemental model of retrospective revaluation without within-compound associations
}

\author{
Patrick C. Connor • Vincent M. Lolordo •
}

Thomas P. Trappenberg

Published online: 30 January 2014

(C) Psychonomic Society, Inc. 2014

Erratum to: Learn Behav

DOI 10.3758/s13420-013-0112-z

There was an sign error in Equation 5, which appeared as:

$\Delta u_{j}=\frac{1}{\tau}\left(u_{j}-\left(\frac{1}{N} \sum_{i=1}^{N} S_{i} w_{i j}^{I}-\frac{1}{M} \sum_{k=1}^{M} r\left(u_{k}\right) w_{k j}^{L}\right)\right)$

The equation should have read:

$\Delta u_{j}=\frac{1}{\tau}\left(-u_{j}+\left(\frac{1}{N} \sum_{i=1}^{N} S_{i} w_{i j}^{I}-\frac{1}{M} \sum_{k=1}^{M} r\left(u_{k}\right) w_{k j}^{L}\right)\right)$

The simulations in the paper used the correct signs, so that the simulated results and conclusions remain the same.

The online version of the original article can be found at http:dx.doi.org/ 10.3758/s13420-013-0112-z.

P. C. Connor $(\bowtie) \cdot$ T. P. Trappenberg

Faculty of Computer Science, Dalhousie University,

Halifax, Nova Scotia, Canada

e-mail: patrick.connor@dal.ca

V. M. Lolordo

Department of Psychology, Dalhousie University,

Halifax, Nova Scotia, Canada 